University of Wollongong

Research Online

Faculty of Engineering and Information

Faculty of Engineering and Information

Sciences - Papers: Part A

Sciences

$1-1-1996$

Precursory localization and development of microfractures along the ultimate fracture plane in amphibolite under triaxial creep

Takashi Satoh

Geological Survey Of Japan

Shivakumar Karekal

National Institute of Rock Mechanics, skarekal@uow.edu.au

Osamu Nishizawa

Geological Survey Of Japan

K Kusunose

Geological Survey Of Japan

Follow this and additional works at: https://ro.uow.edu.au/eispapers

Part of the Engineering Commons, and the Science and Technology Studies Commons

Research Online is the open access institutional repository for the University of Wollongong. For further information contact the UOW Library: research-pubs@uow.edu.au 


\title{
Precursory localization and development of microfractures along the ultimate fracture plane in amphibolite under triaxial creep
}

\author{
Abstract \\ In a triaxial creep experiment in amphibolite, we clearly found a precursorylo calizationa nd developmento \\ $f$ microfracturesa long the final fracture planeu singa $n A E$ (acoustice missions) ourcelo cation \\ technique.T he precursorylo calizationo $f A E$ hypocenters first nucleatedn ear a pre-existingm \\ acroscopidc efecta ndt hene xtendedg raduallya longt hef inalf racture plane prior to failure. On the other \\ hand, no significant precursorylo calizationo $f A E$ hypocenteros $n$ the final fracture plane before failure \\ has been reported in rock samplesf ree of pre-existingm acroscopidce fects. This differencein $A E$ \\ occurrencep atterns beforef ailure could be explainedb y the differencein the degreeo $f$ damage in the \\ portion of the rock surrounding the localization zone when it nucleates.

\section{Keywords} \\ triaxial, under, amphibolite, plane, fracture, ultimate, along, microfractures, development, creep, \\ localization, precursory \\ Disciplines \\ Engineering | Science and Technology Studies

\section{Publication Details} \\ Satoh, T., Karekal, S., Nishizawa, O. \& Kusunose, K. (1996). Precursory localization and development of \\ microfractures along the ultimate fracture plane in amphibolite under triaxial creep. Geophysical Research \\ Letters, 23 (8), 865-868.
}




\title{
Precursory localization and development of microfractures along the ultimate fracture plane in amphibolite under triaxial creep
}

\author{
Takashi Satoh $^{1}$, Karekal Shivakumar ${ }^{2}$, Osamu Nishizawa ${ }^{1}$, \\ and Kinichiro Kusunose ${ }^{1}$
}

\begin{abstract}
In a triaxial creep experiment in amphibolite, we clearly found a precursory localization and development of microfractures along the final fracture plane using an $\mathrm{AE}$ (acoustic emission) source location technique. The precursory localization of $\mathrm{AE}$ hypocenters first nucleated near a pre-existing macroscopic defect and then extended gradually along the final fracture plane prior to failure. On the other hand, no significant precursory localization of $\mathrm{AE}$ hypocenters on the final fracture plane before failure has been reported in rock samples free of pre-existing macroscopic defects. This difference in $\mathrm{AE}$ occurrence patterns before failure could be explained by the difference in the degree of damage in the portion of the rock surrounding the localization zone when it nucleates.
\end{abstract}

\section{Introduction}

Using loading apparatuses that can deform a brittle rock sample quasi-statically throughout its entire fracture process, Wong [1982] and Lockner et al. [1991] found that localization of microfractures on the macroscopic fracture plane usually occurs at almost the same time that the peak differential stress is attained. It is expected from their results that, if we deform a brittle rock sample with a conventional loading machine, few indications of fault nucleation can be detected, because the sample fractures violently in a fraction of a second when the differential stress reaches the strength of the sample. However, several authors have reported precursory localization of microfractures around the final macroscopic fault by using holographic interferometry [e.g., Spetzler et al., 1977] and AE (acoustic emission) source location [e.g., Lockner and Byerlee, 1980] techniques.

Development of microfractures in space and time is of primary importance for understanding the fault formation process in rock. In order to see the microfracturing process, $\mathrm{AE}$ source location has a major advantage in that it can detect the three-dimensional distribution of microfractures, while holographic interferometry can

\footnotetext{
${ }^{1}$ Geological Survey of Japan, Tsukuba, Japan.

${ }^{2}$ National Institute of Rock Mechanics, Kolar Gold Fields, India.

Copyright 1996 by the American Geophysical Union.
}

Paper number $96 \mathrm{GL} 00739$

0094-8534/96/96GL-00739\$05.00 only detect deformation on the sample surface. Among a number of rock fracture experiments under various loading conditions that we have completed [e.g., Satoh et al., 1986, 1990; Lei et al., 1992], we have only twice found clear evidence of precursory localization of $\mathrm{AE}$ hypocenters around the final macroscopic fault plane: once in granite in a triaxial cyclic loading experiment [Satoh et al., 1990], and more recently in amphibolite in a triaxial creep experiment. In this paper, we discuss which case such precursory localization of microfractures is sometimes observed on the basis of the experimental results of the amphibolite creep experiment. We also discuss microfracturing that occurred during formation of a macroscopic fracture plane by means of $\mathrm{AE}$ focal mechanism.

\section{Experiment}

A fine grained amphibolite sample was collected from the $700 \mathrm{~m}$ depth level of the Champion Reefs Mine, Kolar Gold Fields, India. A right circular cylinder 50 $\mathrm{mm}$ in diameter and $100 \mathrm{~mm}$ in length was precisely prepared. The sample contained a healed vertical joint about $1 \mathrm{~mm}$ in mean aperture dividing it into two equal halves.

$\mathrm{AE}$ waveforms were detected using 16 longitudinal type piezoelectric transducers; 14 on the sample side surface and 2 in the end-pieces attached to the top and bottom ends of the sample. Six cross-type metal foil strain gauges $5 \mathrm{~mm}$ in length were bonded along the sample mid-plane at $60^{\circ}$ intervals to measure axial and circumferential strains.

The sample was subjected to a constant differential stress of $570 \mathrm{MPa}$ at a confining pressure of $30 \mathrm{MPa}$, which is about $85 \%$ of the short-term fracture strength. Figure 1 shows the observed strains as functions of differential stress for the loading stage and of time for the creep stage. The ultimate fracture occurred in a violent manner about 114 minutes after the beginning of creep, and the macroscopic fracture plane was formed as shown in Figure 2. The fracture plane was oriented at about $20^{\circ}$ with respect to the maximum compression axis, a typical orientation for triaxial compression [Paterson, 1978].

\section{Results}

Figure 2 shows the temporal change of the AE hypocenter distribution during the creep stage. Hypocenters 


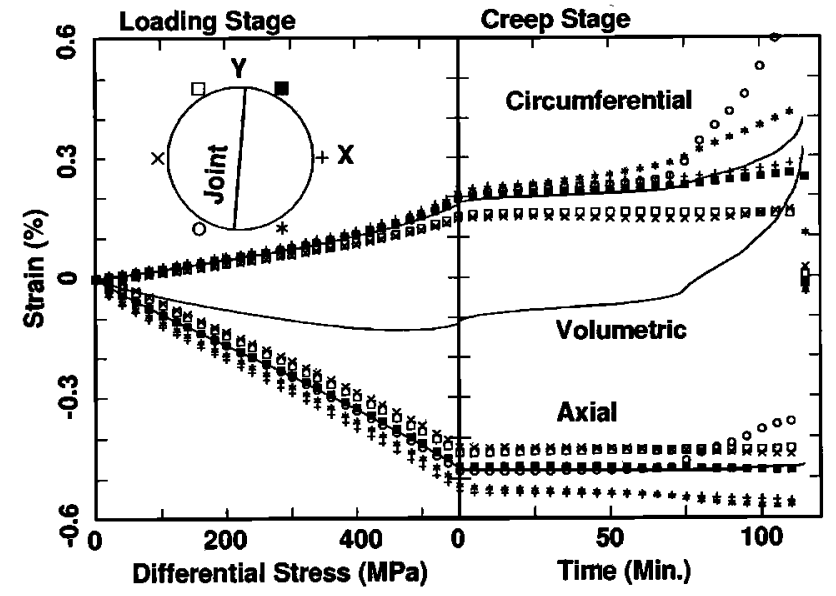

Figure 1. Strains as functions of differential stress during the loading stage (left) and of time during the creep stage (right). The solid lines indicate the average strains. Symbols indicate positions of the strain gauges.

are plotted for the events which were located with a probability error smaller than $2 \mathrm{~mm}$. The time intervals are selected so that we can see the temporal change of the distribution pattern clearly.

During the first 60 minutes after the beginning of creep, most $\mathrm{AE}$ events were concentrated on a lin- ear segment, located along the intersection of the preexisting joint and the final fracture plane (Figure 2(a)). A composite focal mechanism for the events in this linear cluster is shown in Figure 3(a). Neither of the two nodal planes of the focal mechanism solution coincide with the pre-existing joint. Instead, one of the nodal planes ( $\mathrm{C}$ in Figure 3(a)) is roughly parallel to the AE cluster and perpendicular to the pre-existing vertical joint. From this focal mechanism solution, we can speculate that these $\mathrm{AE}$ events resulted from normal faulting on a thin linear crease that forms a small jog on the pre-existing joint surface. Thus, the reproducibility of these experimental results is not expected. In spite of this, the results provide us important information about the failure process of rock samples containing pre-existing macroscopic defects.

The linear AE cluster shown in Figure 2(a) remained active until fracture (Figure 2(b)-(e)). However, during the second interval, $\mathrm{AE}$ activity in the region where the linear cluster intersected the sample surface began to broaden (Figure 2(b)), and it continued to extend along the circumferential surface on the final fracture plane (Figure 2(c)-(e)). From the average volumetric strain (Figure 1), it appears that tertiary creep started at about 70 minutes. However, the local strains were very uneven. Two strain gauges close to the place where the precursory $\mathrm{AE}$ activity nucleated ( $\mathrm{o}$ and $*$ in Figure
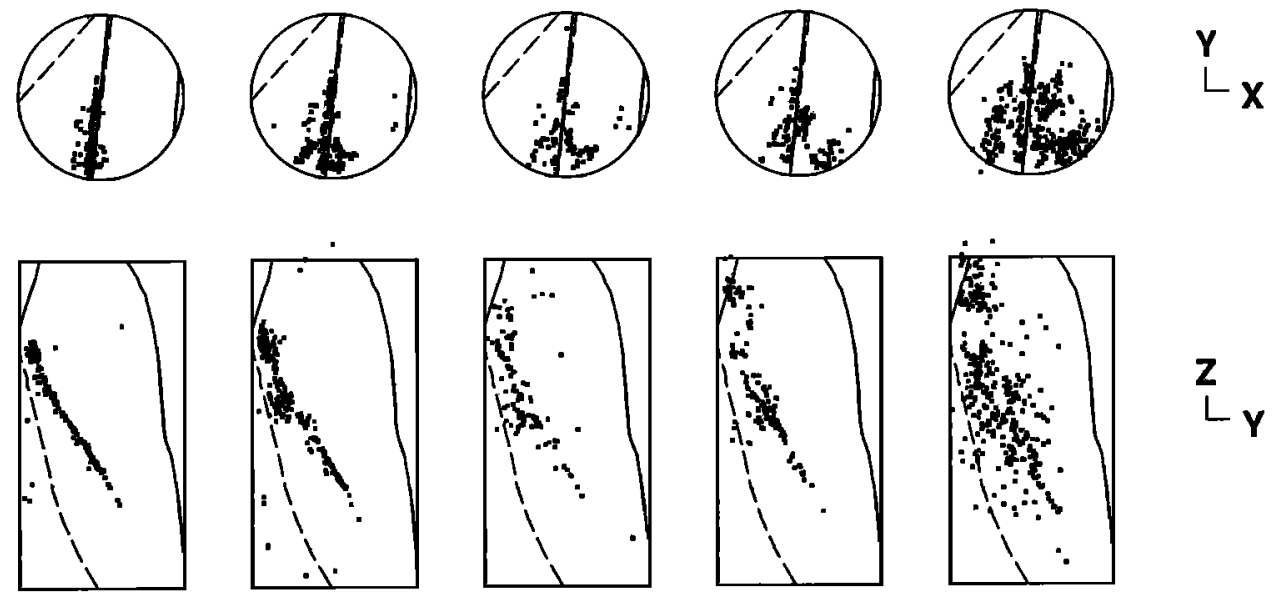

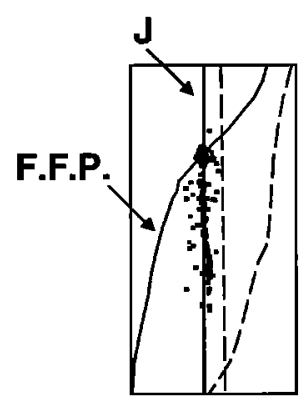

(a)

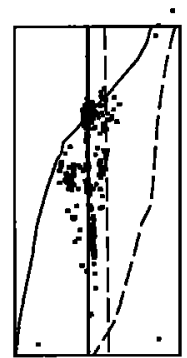

(b)

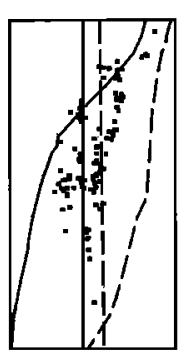

(c)

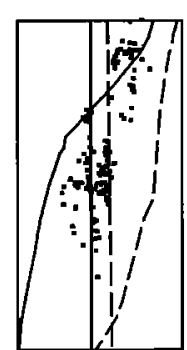

(d)

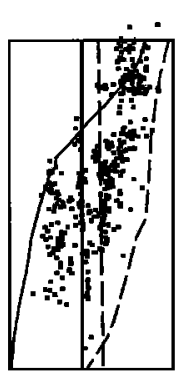

(e)

Figure 2. Orthographic projection showing the spatial distribution of $A E$ hypocenters during (a) $0-60$, (b) $60-100$, (c) $100-110$, (d) 110-113, and (e) 113-114 minutes from the beginning of creep. Surface traces of the final fracture plane (F.F.P.) and the pre-existing joint (J), which appeared on the front and rear sides of the sample, are drawn by solid and dashed lines, respectively. 

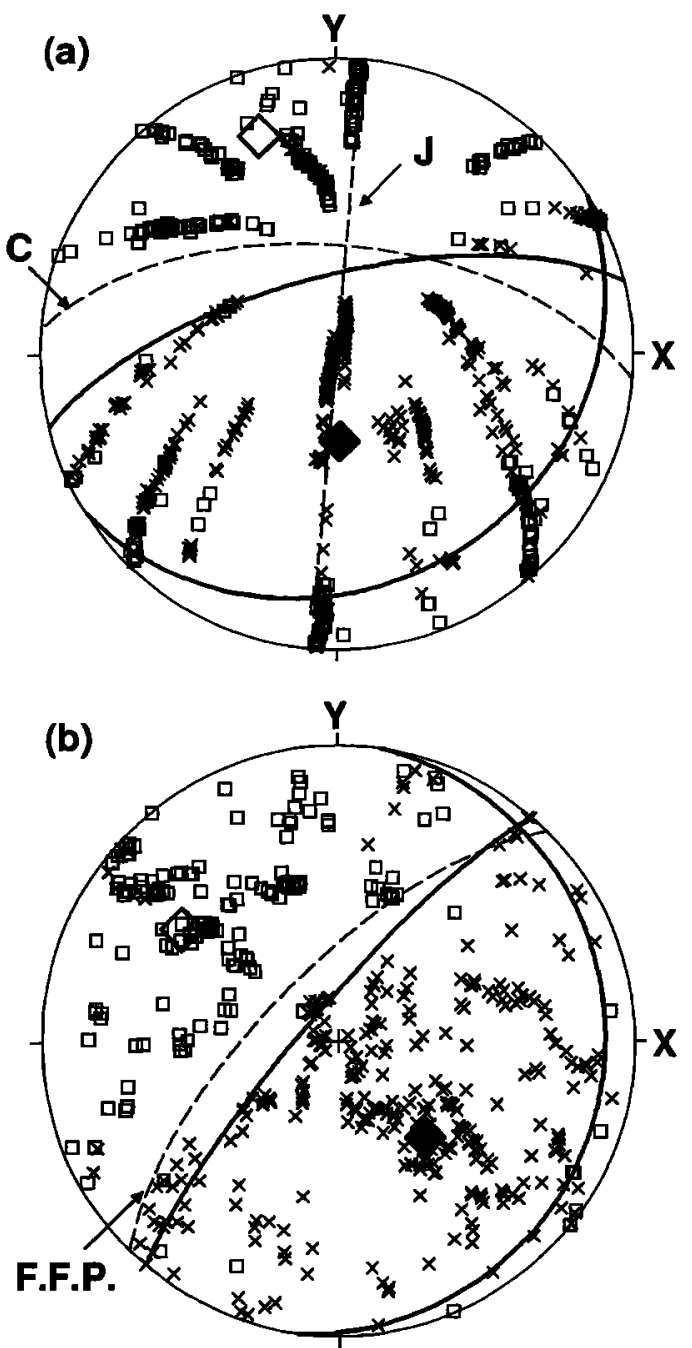

Figure 3. Composite polarity distribution of P-wave first motions and its best-fit, quadrant type focal mechanism solution. Squares and crosses denote compressional and dilatational first motions, respectively. Thick solid lines indicate nodal planes of the focal mechanism solution. Solid and open diamonds represent the $\mathrm{P}$ - and T-axes, respectively. The data are plotted on a lower focal hemisphere by equal area projection. (a) events belonging to the linear cluster shown in Figure 2(a). Dashed line marked by $\mathrm{J}$ indicates the pre-existing vertical joint, and that marked by $C$, the plane parallel to the alignment of the $\mathrm{AE}$ cluster and perpendicular to the pre-existing joint. (b) events plotted in Figure 2(e) except for the events belonging to the linear cluster. Dashed line marked by F.F.P. indicates the final fracture plane.

1) showed remarkable accelerations in circumferential strain.

From the $\mathrm{x}-\mathrm{z}$ projections of the hypocenter distribution in Figure 2, we can see that the $\mathrm{AE}$ activity diminished after the front of the precursory events passed (Figure 2(b)-(e)). Most events that occurred behind the front were those belonging to the linear $\mathrm{AE}$ cluster. A similar distribution pattern of $\mathrm{AE}$ hypocenters was found during the post-failure stage in a Westerly granite triaxial compression experiment conducted by
Lockner et al. [1991]. They concluded that these AE events occurred in the process zone ahead of the slowly expanding macroscopic fracture plane. Their interpretation supports the idea that the distribution pattern of the $\mathrm{AE}$ hypocenters found in Figure 2(b)-(e) resulted from quasi-static growth of the final fracture plane prior to failure. Figure 3(b) shows a composite distribution of the first motion polarities for the events plotted in Figure 2(e), except for the events belonging to the linear cluster. The distribution can be well fit by a quadrant type focal mechanism solution whose steeper nodal plane is almost coincident with the macroscopic fracture plane.

\section{Discussion}

The focal mechanism solution shown in Figure 3(b) is the first solution for the events which occurred in the process zone, and provides us with a very important clue to the fault formation process in rock. It is noted that this focal mechanism is apparently different from that for the linear cluster (Figure 3(a)). This suggests that the events which occurred in the process zone were not greatly affected by the existence of the pre-existing joint, but represents some general feature of microfracturing in the process zone. It has been reported that shear type $\mathrm{AE}$ events become dominant approaching final fracture in fine grained andesite [Satoh et al., 1986] and in medium grained granite [Satoh et al., 1990; Lei et al., 1992]. They interpreted that these events occurred by crack-crack interaction (connection of cracks by sliding). The focal mechanism solution shown in Figure 3(b) indicates that, in the process zone ahead of the macroscopic fault, crack-crack interaction was the dominant process of microfracturing. This result is consistent with recent theoretical and experimental studies on fault nucleation and growth process in rock [e.g., Reches and Lockner, 1994; Moore and Lockner, 1995]. In order to understand the crack-crack interaction occurring in the process zone, it is very important to know which nodal plane corresponds to the shear crack. From a microscopic observation of Westerly granite samples, Moore and Lockner [1995] suggest that linking cracks with a shear crack at a small angle to the maximum compression axis occurs just in front of the macroscopic fault. Kranz [1979] found, from scanning electron microscope observations of an uniaxially stressed Barre granite, an example of en echelon linkage by shear cracks whose planes are almost perpendicular to the maximum compression axis. Thus, at present, we can not reject the either of the two possibilities.

A failure process similar to that presented here was observed in the granite cyclic loading experiment reported by Satoh et al. [1990] . A cluster of AE hypocenters appeared in an early stage of the experiment. Satoh et al. [1990] interpreted this cluster to be due to a pre-existing macroscopic defect. The precursory localization of $\mathrm{AE}$ activity nucleated near this early cluster and extended gradually along the final fracture plane, followed by the ultimate failure. In both experiments, 
the precursory nucleation and development of a macroscopic fracture plane was induced by a pre-existing macroscopic defect probably due to stress concentration around it. AE clustering from early stage of loading on the eventual fracture plane was also observed in triaxial compression experiments on sandstone conducted by Lockner et al. [1992]. Lockner [1993] and Lockner et al. [1992] attributed these early AE clusters to the presence of a pre-existing weak zone. Our experimental results support their interpretation. On the other hand, no significant precursory localization of $\mathrm{AE}$ hypocenters on the final fracture plane has been reported when we deformed rock samples free of pre-existing macroscopic defects. Lockner et al. [1991] were able to follow quasistatically the entire fracture process of a brittle granite sample by controlling the axial load so as to maintain a constant $\mathrm{AE}$ occurrence rate. They found from $\mathrm{AE}$ source locations that fault nucleation occurred at the sample surface soon after the peak stress was attained, and that the fault plane grew across the sample, accompanied by a gradual drop in axial load. If we deform a similar rock sample with a conventional loading apparatus, we would expect to detect little precursory localization of $\mathrm{AE}$ hypocenters because the fracture process after the peak stress would occur violently in a fraction of a second. This difference in the $\mathrm{AE}$ occurrence pattern before failure could be explained by a difference in the degree of damage in the region surrounding the fault zone when it nucleates.

Acknowledgments. The AE measurement system has been developed by X. Lei. We would like to thank him for his support of the experiment. We also thank S. R. Carlson for his helpful comments and suggestions.

\section{References}

Kranz, R. L., Crack-crack and crack-pore interactions in stressed granite, Int. J. Rock Mech. Min. Sci. \& Geomech. Abstr., 16, 37-47, 1979.

Lei, X, O.Nishizawa, K.Kusunose and T.Satoh, Fractal structure of the hypocenter distributions and focal mechanism solutions of acoustic emission in two granites of different grain sizes, J. Phys. Earth, 40, 617-634, 1992.
Lockner, D.A., The role of acoustic emission in the study of rock fracture, Int. J. Rock Mech. Min. Sci. \& Geomech. Abstr., 30, 883-899, 1993.

Lockner, D.A., and J.D.Byerlee, Development of fracture planes during creep in granite, in 2nd Conf. on Acoustic Emission/Microseismic Activity in Geological Structures and Materials, Trans Tech Publications, 11-25, 1980.

Lockner, D.A., J.D.Byerlee, V.Kuksenko, A.Ponomarev and A.Sidorin, Quasi-static fault growth and shear fracture energy in granite, Nature, 359, 39-42, 1991.

Lockner, D.A., J.D.Byerlee, V.Kuksenko, A.Ponomarev and A.Sidorin, Observation of quasistatic fault growth from acoustic emissions, in Fault Mechanics and Transport Properties of Rocks, edited by B. Evans and T.-f. Wong, pp.3-31, Academic Press, 1992.

Moore, D.E., and Lockner, D.A., The role of microcracking in shear-fracture propagation in granite, J. Struct. Geol., 17, 95-114, 1995.

Paterson, M.S., Experimental Rock Deformation- The Brittle Field, Springer-Verlag, 1978.

Reches, Z., and Lockner, D.A., Nucleation and growth of faults in brittle rocks, J. Geophys. Res., 99, 18159-18175, 1994.

Satoh, T, O.Idehara, O.Nishizawa and K.Kusunose, Hypocenter distribution and focal mechanisms of $\mathrm{AE}$ events under triaxial compression -focal mechanisms of AE events in Yugawara andesite- (in Japanese), J. Seism. Soc. Jpn., 39, 351-360, 1986.

Satoh, T., O.Nishizawa and K.Kusunose, Fault development in Oshima granite under triaxial compression inferred from hypocenter distribution and focal mechanism of acoustic emission, Tôhoku Geophys. J., (Sci. Rep. Tôhoku Univ., Ser.5), 33, 241-250, 1990.

Spetzler, H., N.Soga, H.Mizutani and R.J.Martin III, Strain field associated with fracture under high pressure, viewed with holographic interferometry, in High-Pressure Research: Applications in Geophysics, edited by M. H. Manghnani and S. Akimoto, pp.625-635, Academic Press, 1977.

Wong, T.-f., Micromechanics of faulting in Westerly granite, Int. J. Rock Mech. Min. Sci. \& Geomech. Abstr., 19, 49-64, 1982.

T.Satoh, O.Nishizawa and K. Kusunose, Geological Survey of Japan, 1-1-3, Higashi, Tsukuba, Ibaraki, 305 Japan (e-mail: satoh@gsj.go.jp)

K. Shivakumar, National Institute of Rock Mechanics, Kolar Golds Fields, Karnataka, 563-117 India

(received September 18, 1995; revised January 5, 1996; accepted January 23, 1996.) 